\title{
ESPACIALIZAÇÃO DO PERÍODO DE VERANICO PARA DIFERENTES NÍVEIS DE PERDA DE PRODUÇÃO NA CULTURA DO MILHO, NA BACIA DO RIO VERDE GRANDE, MG
}

\author{
Daniel Fonseca de Carvalho', Roberto Araújo de Faria $^{2}$, Sérgio Antônio Veronez de Sousa ${ }^{3}$ \& \\ Henrique Queiroz Borges ${ }^{4}$
}

\begin{abstract}
RESUMO
Realizou-se um estudo para estimar as perdas relativas na produção de milho, provocadas por deficiência hídrica na fase de floração, e espacializar os períodos de veranico, em dias, para perdas de 10, 20, 30 e 50\%, na bacia do Rio Verde Grande, MG. A duração do veranico nessa bacia variou de 2 a 4 dias, de 3 a 7 dias, de 4 a 9 dias e de 5 a 11 dias, para perdas na produção de milho, na fase de floração em outubro, de 10,20,30 e 50\%, respectivamente. A cultura demonstrou ser mais sensível ao veranico na região norte da bacia, para a época de semeadura estudada, merecendo uma análise criteriosa com relação ao cultivo desta cultura, em condições de sequeiro.
\end{abstract}

Palavras-chave: veranico, método Monte Carlo, milho

\section{SPATIALIZATION OF THE DROUGHT DURATION FOR DIFFERENT CORN PRODUCTION LOSS LEVELS IN RIO VERDE GRANDE WATERSHED, MINAS GERAIS STATE, BRAZIL}

\begin{abstract}
A study was performed to determine the relative loss in corn production during the flowering season and to determine the drought period for losses of 10, 20, 30 and 50\%, in Rio Verde Grande watershed, Minas Gerais, Brazil. The drought period varied from 2 to 4,3 to 7, 4 to 9 and 5 to 11 days, during the flowering stage for loss in corn production of 10,20,30 e 50\%, respectively. The corn crop is more sensitive in the north region of watershed for the studied planting period and requires a critical analysis of cultivation of this crop under rainfed conditions.
\end{abstract}

Key words: drought, Monte Carlo method, corn

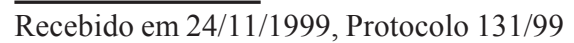

${ }^{1}$ Prof. Adjunto, DE/IT/UFRRJ. CEP 23851 - 970, Seropédica, RJ. Fone: (0xx21) 682 1865. E-mail: carvalho@ufrrj.br

${ }^{2}$ M.S. em Eng. Agrícola. Doutorando em Economia Rural, UFV. CEP 36571 - 000, Viçosa, MG. E-mail: raf@alunos.ufv.br

${ }^{3}$ D.S. em Agronomia. Professor na UNOESTE. Presidente Prudente, SP. E-mail: savsousa@apecnt.unoeste.br

${ }^{4}$ M.S. em Eng. Agrícola. Técnico da EMATER, Araçuaí, MG 


\section{INTRODUÇÃO}

Quase todo o Estado de Minas Gerais apresenta-se com duas estações bem definidas: uma chuvosa, que vai de outubro até março, e outra, caracterizada por um período de seca, que se estende de abril a setembro. É durante o período chuvoso que as principais culturas anuais são cultivadas e são dependentes somente da precipitação pluvial, como fonte de água (Castro Neto \& Villela, 1986).

Como a água é um dos fatores que mais influenciam no rendimento das culturas, o sucesso da produção agrícola, principalmente em áreas não irrigadas, depende das características do regime pluviométrico local. Desta forma, o conhecimento sobre a duração, quantidade e distribuição das chuvas, é fundamental para o planejamento das atividades agrícolas e para definição das datas mais apropriadas ao preparo do solo e plantio.

A precipitação total do período chuvoso é suficiente para o desenvolvimento da agricultura na zona intertropical, porém ela é afetada pelo veranico, fenômeno que se caracteriza por períodos de interrupção da precipitação durante a estação chuvosa. A influência do veranico sobre a produtividade das culturas pode ser acentuada, principalmente quando coincide com a fase na qual a planta é mais sensível à deficiência hídrica. No cerrado, o veranico coincide, muitas vezes, com o período de florescimento da planta, ou seja, na fase mais sensível. Espinoza et al. (1980) encontraram, para a cultura do milho, perdas na ordem de 20 a $70 \%$ em função da densidade de plantio para as variedades mais resistentes ao déficit hídrico, com veranico acontecendo na época de reprodução.

A previsão da ocorrência dos veranicos para uma região é fundamental e, aliada às conseqüentes perdas que este veranico pode acarretar, torna-se ferramenta importante para o desenvolvimento da agricultura com menor risco para o produtor (Sousa \& Peres, 1996).

Paiva (1997) e Ribeiro et al. (1998) interpolaram, utilizando um sistema de informações geográficas, valores pontuais georreferenciados das probabilidades de ocorrência dos veranicos, de 7,10 e 15 dias de duração para as bacias hidrográficas dos rios Doce e Paracatu, respectivamente, mas não contabilizaram o efeito deste fenômeno na produção das culturas.

Com o presente trabalho, teve-se por objetivo estimar as perdas relativas na produção de milho, influenciadas pela ocorrência de veranico na fase de floração, e espacializar os períodos de veranico, em dias, para perdas de 10, 20, 30 e 50\%, na bacia do Rio Verde Grande.

\section{MATERIAL E MÉTODOS}

Para a realização deste trabalho foram utilizados dados diários de precipitação, temperatura máxima e temperatura mínima coletados nas estações meteorológicas pertencentes ao Instituto Nacional de Meteorologia (INMET) cujas características são apresentadas na Tabela 1 .

A Figura 1 apresenta a bacia hidrográfica do Rio Verde Grande e a localização das estações consideradas neste trabalho. Com uma área de aproximadamente $27.000 \mathrm{~km}^{2}$, a bacia se localiza na região norte do Estado de Minas Gerais, entre as latitudes Sul $17^{\circ} 00^{\prime}$ e $15^{\circ} 30^{\prime}$ e longitude W.GR $44^{\circ} 15^{\prime}$ e $42^{\circ} 30^{\prime}$.

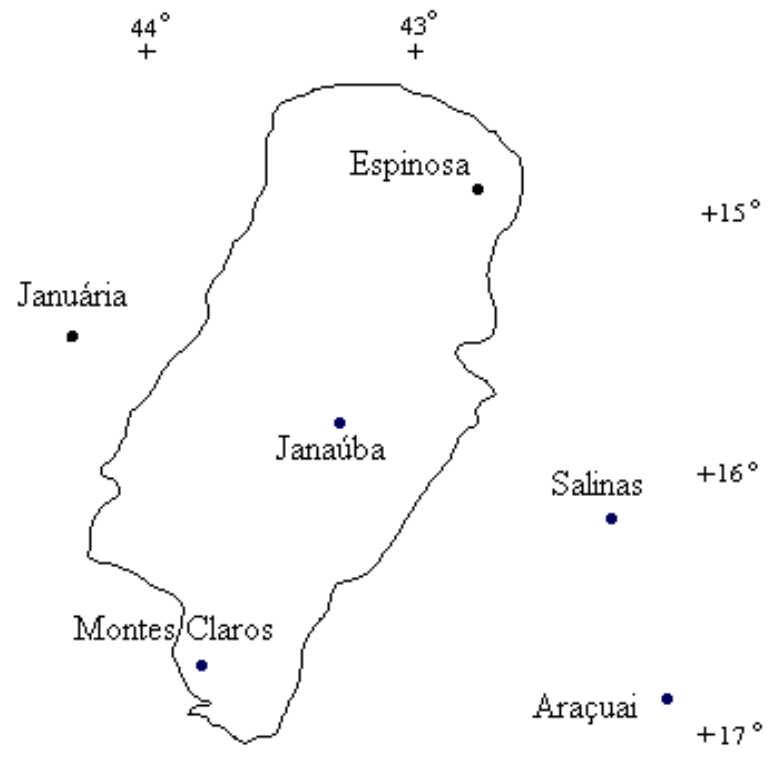

Pirapora

-

\section{Itamarandiba}

Figura 1. Localização das estações meteorológicas estudadas

De acordo com a classificação climática de Köppen, a região apresenta clima do tipo AW (tropical chuvoso, clima de savana com inverno seco) (Antunes, 1980).

Para cada localidade, a lâmina de irrigação no ciclo da cultura do milho, para plantio diário ao longo do ano, foi simulada utilizando-se metodologia descrita por Sousa (1993) que considera a necessidade térmica correspondente a cada estádio de desenvolvimento da cultura do milho (graus-dias) além da lâmina de precipitação dependente, a nível de $75 \%$ de probabilidade de ocorrência. Em razão do plantio no mês de

Tabela 1. Características das estações climatológicas selecionadas

\begin{tabular}{clcccrrr}
\hline \multirow{2}{*}{ Cód. } & \multirow{2}{*}{ Nome da Estação } & \multirow{2}{*}{ Latitude } & \multirow{2}{*}{ Longitude } & \multirow{2}{*}{ Altitude $(\mathrm{m})$} & \multicolumn{3}{c}{ Séries Disponíveis } \\
\cline { 5 - 7 } & & $14^{\circ} 56^{\prime}$ & $42^{\circ} 49^{\prime}$ & 570 & 1974 & 1978 \\
\hline 83338 & Espinosa & $15^{\circ} 29^{\prime}$ & $44^{\circ} 22^{\prime}$ & 474 & 1961 & 1978 \\
83386 & Januária & $11^{\circ} 47^{\prime}$ & $43^{\circ} 18^{\prime}$ & 516 & 1984 & 1994 \\
83395 & Janaúba & $16^{\circ} 43^{\prime}$ & $43^{\circ} 52^{\prime}$ & 646 & 1961 & 1978 \\
83437 & Montes Claros & $16^{\circ} 10^{\prime}$ & $42^{\circ} 17^{\prime}$ & 471 & 1961 & 1978 \\
83441 & Salinas & $16^{\circ} 52^{\prime}$ & $42^{\circ} 04^{\prime}$ & 284 & 1961 & 1978 \\
83442 & Araçuaí & $17^{\circ} 21^{\prime}$ & $44^{\circ} 57^{\prime}$ & 505 & 1961 & 18 \\
83483 & Pirapora & $17^{\circ} 51^{\prime}$ & $42^{\circ} 51^{\prime}$ & 1097 & 1962 & 18 \\
83488 & Itamarandiba & & & & 1978 \\
\hline
\end{tabular}


setembro apresentar, para todas as localidades, menor demanda de irrigação suplementar, foram adotados os meses de setembro, como plantio, e outubro, como aquele em que é observada a ocorrência da maior parte do período de floração.

Para a simulação da ocorrência do veranico e da respectiva perda de produção, foi utilizado o software "VERANICO", desenvolvido por Sousa \& Peres (1996) que se baseia no método de simulação Monte Carlo. Neste programa, foram necessários o fornecimento de dados de precipitação, evapotranspiração, o solo e a cultura. Toda a simulação foi realizada para o mês de outubro, uma vez que a fase de floração se caracteriza como aquela mais sensível ao déficit hídrico.

A evapotranspiração foi estimada diariamente, para cada ano da série histórica, utilizando-se o método de Hargreaves, conforme Jensen et al. (1990). Foram considerados dias secos aqueles em que a precipitação foi inferior à lâmina evapotranspirométrica média do mês, para cada localidade.

De posse dos arquivos de dados diários de precipitação, foram identificados os períodos de duração do veranico e suas respectivas freqüências de ocorrência.

Na Tabela 2 são apresentados os parâmetros físico-hídricos representativos do solo de cada localidade, necessários para a estimativa do balanço de água no solo durante o intervalo de duração do veranico. Com exceção de Janaúba, onde foram considerados dados obtidos por Almeida (1997) os parâmetros do solo são apresentados por EMBRAPA (1979).

Tabela 2. Valores de capacidade de campo (CC), ponto de murcha

(PM) e densidade aparente (Dap) representativos dos solos de cada localidade estudada

\begin{tabular}{|c|c|c|c|}
\hline \multirow[t]{2}{*}{ Localidade } & $\mathrm{CC}$ & PM & \multirow{2}{*}{$\begin{array}{c}\text { Dap } \\
\mathrm{kg} \mathrm{dm}^{-3}\end{array}$} \\
\hline & \multicolumn{2}{|c|}{$\mathrm{g} \mathrm{kg}^{-1}$} & \\
\hline Espinosa & 125 & 90 & 1,15 \\
\hline Januária & 135 & 80 & 1,40 \\
\hline Janaúba & 180 & 100 & 1,40 \\
\hline Montes Claros & 220 & 170 & 1,40 \\
\hline Salinas & 135 & 80 & 1,40 \\
\hline Araçuaí & 320 & 200 & 1,40 \\
\hline Pirapora & 320 & 200 & 1,40 \\
\hline Itamarandiba & 135 & 80 & 1,40 \\
\hline
\end{tabular}

Para o cálculo da produção relativa em relação à produção máxima da cultura do milho, foram utilizados os fatores de resposta da cultura à água $(\mathrm{ky})$ de $0,40,1,50,0,50$ e 0,20 para os períodos vegetativo, floração, enchimento de grãos e maturação, respectivamente (Doorenbos \& Kassam, 1994). A equação que representa o efeito do estresse hídrico na planta pode ser apresentada por:

$$
(1-\mathrm{Yr} / \mathrm{Ym})=\mathrm{ky}(1-\mathrm{ETr} / \mathrm{ETm})
$$

em que:

Yr - rendimento real obtido, $\mathrm{kg} \mathrm{ha}^{-1}$

Ym - rendimento máximo obtido, $\mathrm{kg} \mathrm{ha}^{-1}$

ky - coeficiente de resposta da cultura

ETr - evapotranspiração real, $\mathrm{mm} \mathrm{dia}^{-1}$

ETm - evapotranspiração máxima, $\mathrm{mm} \mathrm{dia}^{-1}$.

A partir dos resultados gerados pelo software, identificaram-se os valores de perda relativa de produção para a cultura do milho na fase de floração; em seguida, esses valores, correspondentes a 10, 2030 e 50\% de perda na bacia do Rio Verde Grande, foram espacializados, utilizando-se o programa SURFER, versão 5.01, utilizado para a confecção de modelos de elevação digital do terreno, a partir de dados pontuais. Como método de interpolação utilizou-se o inverso da potência da distância, adotando-se expoente 3. Neste método, o interpolador trabalha com um raio de busca (distância) que utiliza seis pontos amostrados mais próximos do ponto interpolado; depois, utilizando-se o programa IDRISI 2.0, foram gerados os mapas temáticos referentes à duração do período de veranico para os respectivos níveis de perda de produção, na bacia do Rio Verde Grande.

\section{RESULTADOS E DISCUSSÃO}

As Figuras 2 e 3 apresentam os valores obtidos de perda na produção para a cultura do milho, em percentagem da produção máxima em cada veranico, para a fase de floração no mês de outubro. A Figura 2 apresenta os dados para Salinas, Pirapora, Montes Claros e Januária. Os dados de Janaúba, Itamarandiba, Espinosa e Araçuaí são apresentados na Figura 3. Verifica-se que, para uma mesma localização e à medida que se aumenta a duração do veranico, os níveis de perda aumentam sensivelmente.
A. Salinas

Duração do Veranico (dias)

$\begin{array}{lllllllllll}0 & 1 & 2 & 3 & 4 & 5 & 6 & 7 & 8 & 9 & 10\end{array}$

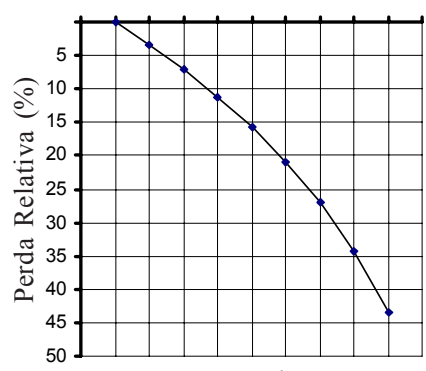

C. Montes Claros

Duração do Veranico (dias)

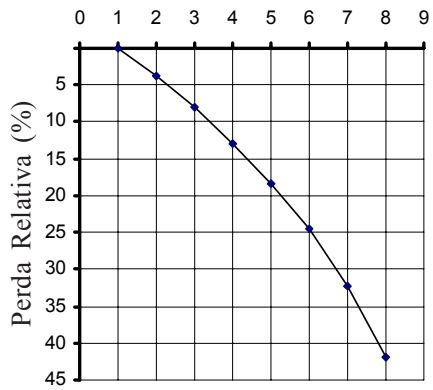

B. Pirapora

Duração do Veranico (dias)

$\begin{array}{lllllllllll}0 & 2 & 4 & 6 & 8 & 10 & 12 & 14 & 16 & 18 & 20\end{array}$

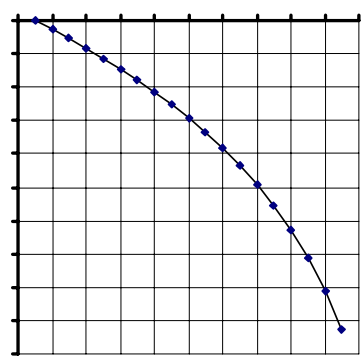

D. Januária

Duração do Veranico (dias) $\begin{array}{llllllllll}0 & 1 & 2 & 3 & 4 & 5 & 6 & 7 & 8 & 9\end{array}$

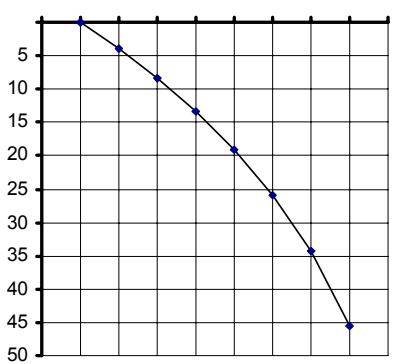

Figura 2. Perda relativa da cultura do milho para cada veranico simulado, na fase de floração e no mês de outubro, para A. Salinas, B. Pirapora, C. Montes Claros e D. Januária

Analisando-se essas figuras, pode-se verificar que, para a maioria das estações, há perdas próximo a $50 \%$, quando a duração do veranico simulado está entre 9 e 12 dias, no período de floração. Para Pirapora e Araçuaí, (Figuras 2B e 3D) respectivamente, a duração do veranico correspondente à perda de $50 \%$ está próximo a 20 dias. Em contrapartida, Espinosa (Figura 3C) apresenta a menor duração de veranico (5 dias) para a mesma ordem de perda. Explica-se este fato pela própria localização das 
A. Janaúba

Duração do Veranico (dias)

$\begin{array}{lllllllllllll}1 & 2 & 3 & 4 & 5 & 6 & 7 & 8 & 9 & 10 & 11 & 12\end{array}$

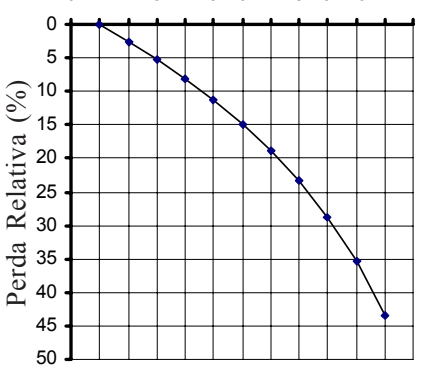

C. Espinosa

Duração do Veranico (dias)

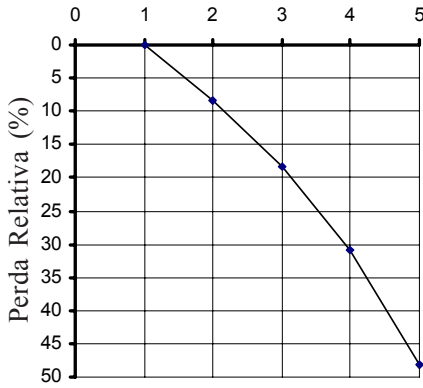

B. Itamarandiba

Duração do Veranico (dias)

$\begin{array}{lllllllllllll}0 & 1 & 2 & 3 & 4 & 5 & 6 & 7 & 8 & 9 & 10 & 11\end{array}$

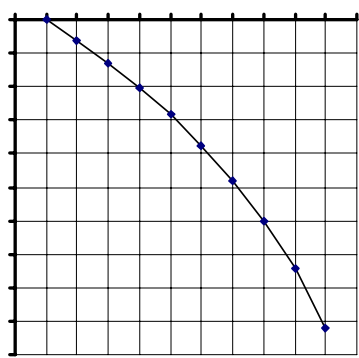

D. Araçuaí

Duração do Veranico (dias) $\begin{array}{lllllllllll}0 & 2 & 4 & 6 & 8 & 10 & 12 & 14 & 16 & 18 & 20\end{array}$

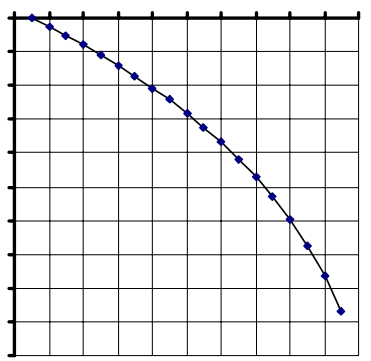

Figura 3. Perda relativa da cultura do milho para cada veranico simulado, na fase de floração e no mês de outubro, para A. Janaúba, B. Itamarandiba, C. Espinosa e D. Araçuaí cidades consideradas, uma vez que Espinosa, situada mais ao norte do Estado, caracteriza-se por um regime pluviométrico mais seco, quando comparada com Pirapora e Araçuaí (Figura 1) além do solo apresentar menor capacidade de retenção de água em relação aos demais.

A Figura 4 apresenta os valores espacializados de duração do veranico para perdas de 10,20,30 e 50\%, para o período da floração, na bacia do Rio Verde Grande.

Para todos os níveis de perda, a região norte da bacia apresentou sempre menor duração do período de veranico. Os maiores valores de duração foram obtidos na região central da bacia.

Pela Figura 4, observa-se que os valores de duração do veranico obtidos nas localidades situadas no interior da bacia, para todos os níveis de perda, influenciaram sensivelmente o resultado da interpolação, considerando-se a área de interesse. Este efeito foi aumentando para maiores níveis de perda da produção. Apesar dos resultados simulados apresentarem grande susceptibilidade da cultura do milho ao veranico, os autores não conhecem nenhum trabalho de campo desenvolvido nesta região, com tal finalidade.

Apesar de Pirapora apresentar as maiores durações de veranico, para todos os níveis de perda, a sua influência foi quase nula para a região sul da bacia, o que pode ser explicado pelo método de interpolação adotado, que utiliza o inverso da distância, além do fato da cidade de Montes Claros se situar nesta região.
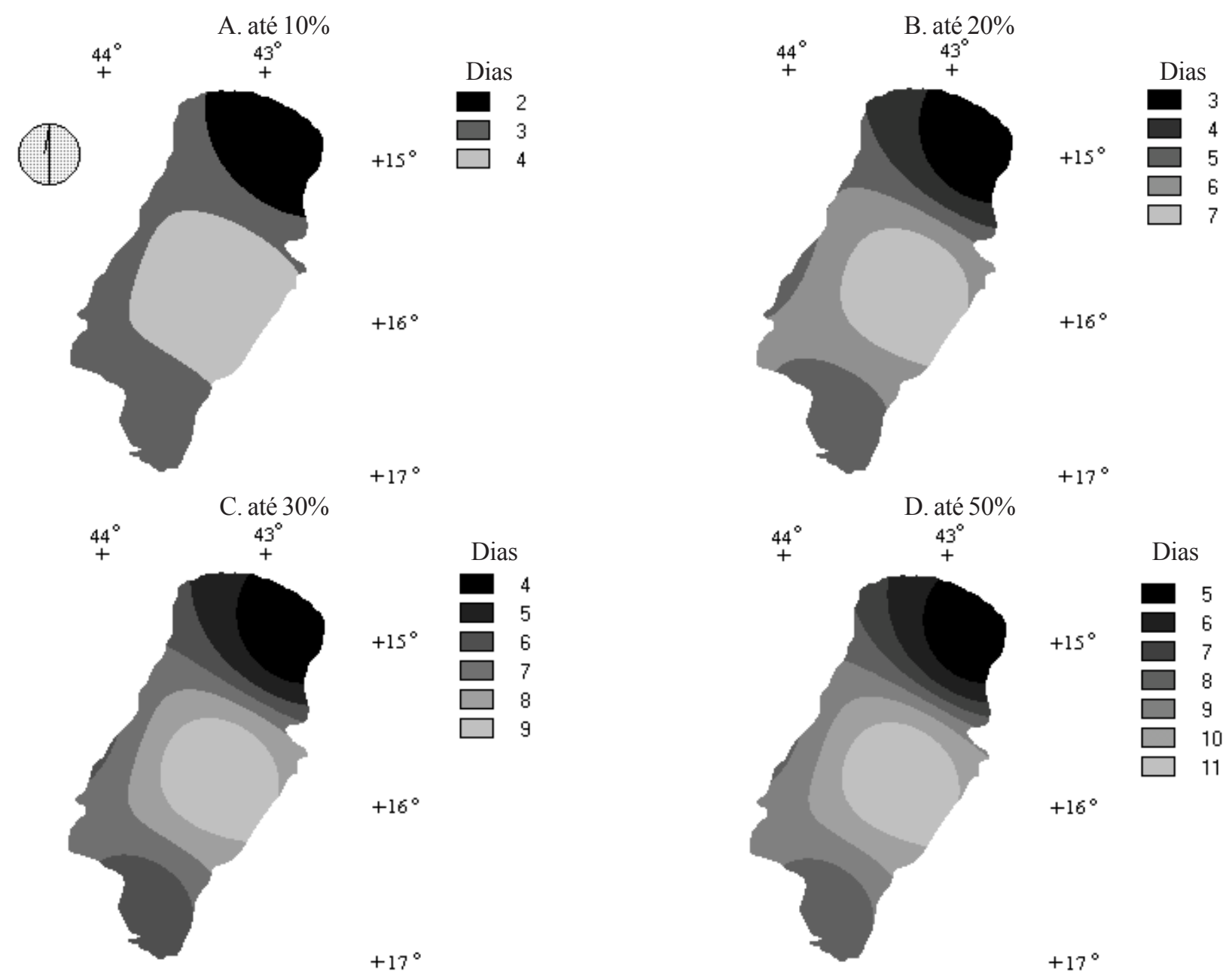

Figura 4. Duração do período de veranico, em dias, para perda relativa de até A. 10\%, B. 20\%, C. 30\% e D. 50\% na produção de milho na Bacia do Rio Verde Grande 
Comparando-se a duração do veranico para as diferentes perdas, verificou-se aumento no número de classes de duração a medida em que se aumenta o nível de perda considerado, fato este que pode ser explicado pela maior amplitude de variação do veranico para maiores níveis de perda (Figuras 2 e 3).

\section{CONCLUSÕES}

1. Para todos os níveis de perda considerados, a região norte da bacia apresentou os menores valores de duração de veranico, seguida da região sul e da região central.

2. A duração simulada do veranico na bacia do Rio Verde Grande variou de 2 a 4 dias, de 3 a 7 dias, de 4 a 9 dias e de 5 a 11 dias, para perdas na produção de milho, na fase de floração em outubro, de 10, 20,30 e 50\%, respectivamente.

3. A cultura do milho demonstrou ser mais sensível ao veranico na região norte da bacia, para a época de plantio estudada, merecendo uma análise criteriosa com relação ao cultivo desta cultura em condições de sequeiro.

4. A metodologia utilizada permitiu a identificação da duração do veranico em qualquer ponto dentro da bacia, sendo indicada para outras regiões, principalmente para aquelas que apresentam baixa disponibilidade de água para irrigação e/ou carência de estações climatológicas.

\section{REFERÊNCIAS BIBLIOGRÁFICAS}

ALMEIDA, F.T. Avaliação dos sistemas de irrigação pressurizados e do manejo da água na cultura da banana no projeto Gorutuba. Viçosa, MG: UFV, 1997. 100p. Dissertação Mestrado
ANTUNES, F.Z. Caracterização climática do cerrado em Minas Gerais. Informe Agropecuário, Belo Horizonte, v.6, n.5, p.52-63, 1980.

CASTRO NETO, P.; VILLELA, E.A. Veranico: um problema de seca no período chuvoso. Informe Agropecuário, Belo Horizonte, v.12, n.138, p.59-62. 1986.

DOORENBOS, J.; KASSAM, A.H. Efeito da água no rendimento das culturas. Campina Grande: UFPB, 1994. 306p. Estudos FAO: Irrigação e Drenagem, 33

ESPINOZA, W.; AZEVEDO, J.; ROCHA, L.D. Densidade de plantio e irrigação suplementar na resposta de três variedades de milho ao déficit hídrico na região de cerrados. Pesquisa Agropecuária Brasileira, Brasília v.15, n.1, p.85-95, 1980.

JENSEN, M.E.; BURMAN, R.D.; ALLEN, R.G. Evapotranspiration and irrigation water requirements. New York: ASCE, 1990.332p.

PAIVA, C. Determinação das datas de início e fim da estação chuvosa e da ocorrência de veranico na bacia do Rio Doce. Viçosa, MG: UFV, 1997, 65p. Dissertação Mestrado

RIBEIRO, A. Espacialização das probabilidades de ocorrência de veranicos de 7, 10 e 15 dias na bacia do Rio Paracatu, Minas Gerais. In: FERREIRA, P.A.; EUCLYDES, H.P. Recursos hídricos e tecnologia necessária aos projetos hidroagrícolas. Viçosa, MG: UFV, RURALMINAS, 1998. p.125-166.

SOUSA, E.F. Modelo computacional aplicado ao manejo e planejamento de irrigação. Viçosa, MG: UFV, 1993, 65p. Dissertação Mestrado

SOUSA, S.A.V.; PERES, F.C. Programa computacional para a simulação da ocorrência de veranicos e queda de produção. In: CONGRESSO BRASILEIRO DE ENGENHARIA AGRÍCOLA, 25, 1996, Bauru. CD Rom... FET-UNESP/SBEA. 